\title{
Filling the Gaps: The Synergistic Application of Satellite Data for the Volcanic Ash Threat to Aviation
}

\author{
John Murray, Jean-Paul Vernier, T. Duncan Fairlie \\ NASA Langley Research Center, Hampton, VA \\ Michael Pavolonis \\ NOAA/NESDIS, Madison, Wisconsin \\ Nickolay A. Krotkov \\ University of Maryland, Baltimore Campus \\ Francis Lindsay, John Haynes \\ NASA Headquarters, Washington, DC
}

\begin{abstract}
Although significant progress has been made in recent years, estimating volcanic ash concentration for the full extent of the airspace affected by volcanic ash remains a challenge. No single satellite, airborne or ground observing system currently exists which can sufficiently inform dispersion models to provide the degree of accuracy required to use them with a high degree of confidence for routing aircraft in and near volcanic ash. Toward this end, the detection and characterization of volcanic ash in the atmosphere may be substantially improved by integrating a wider array of observing systems and advancements in trajectory and dispersion modeling to help solve this problem. The qualitative aspect of this effort has advanced significantly in the past decade due to the increase of highly complementary observational and model data currently available. Satellite observations, especially when coupled with trajectory and dispersion models can provide a very accurate picture of the 3-dimensional location of ash clouds. The accurate estimate of the mass loading at various locations throughout the entire plume, however improving, remains elusive. This paper examines the capabilities of various satellite observation systems and postulates that model-based volcanic ash concentration maps and forecasts might be significantly improved if the various extant satellite capabilities are used together with independent, accurate mass loading data from other observing systems available to calibrate (tune) ash concentration retrievals from the satellite systems.
\end{abstract}

\section{Discussion}

The international community's interest in the safety and economic impacts of the volcanic ash threat to aviation has greatly increased since the eruption of Eyjafjallajökull substantially disrupted aviation operations throughout Europe in April and May of 2010. To respond to this threat, NASA has developed a significant number of critical volcanic ash applications for a wide range of cutting-edge satellite observations. This has entailed the development of many new and innovative technical advances which are improving the accuracy and the utility of volcanic ash advisories worldwide. None of these observations alone, however, provides a panacea for improving volcanic ash advisories. This paper discusses the capabilities of different sensors onboard NASA research satellites, and examines how they can be used synergistically to improve warnings produced by operational Volcanic Ash Advisory Centers. 
An important take-away from this presentation, is that because state-of-the-art atmospheric dispersion models are so highly sensitive to initial conditions, and because no single observing system can adequately describe those which are critical to produce an accurate forecast of the ash cloud, the concomitant employment of multi-disciplinary observations of the source plume and the dispersed ash using a number of observations, is needed to accurately detect, characterize and track volcanic ash. A substantial legacy which rests on NASA Earth Observing Satellites and their advanced data is key.

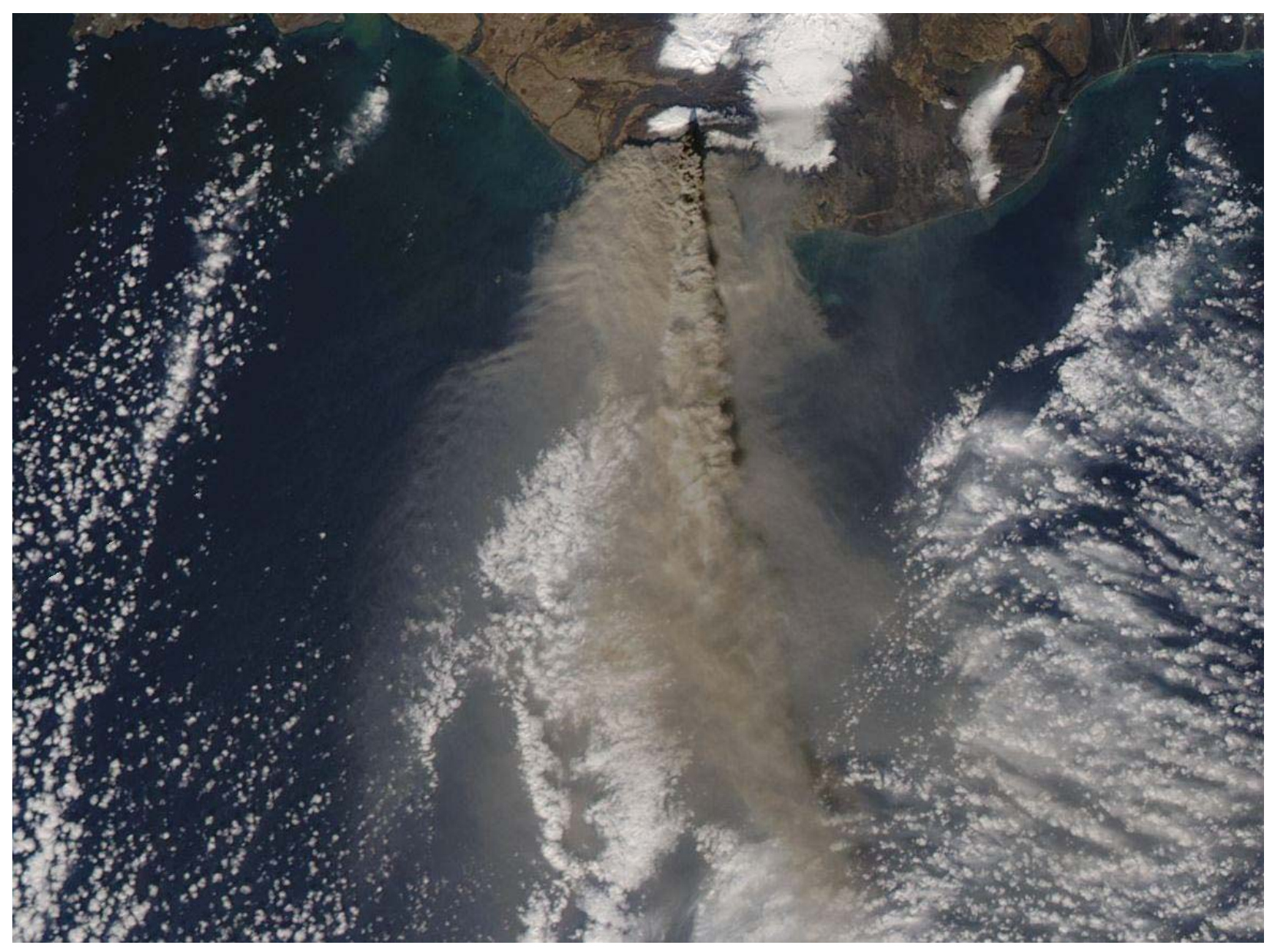

Figure 1. Moderate Resolution Imaging Spectroradiometer (MODIS) image taken on April 17, 2010

For a number of years, a split-window technique has been employed to differentiate volcanic ash from water and ice clouds by differencing the brightness temperatures for the $10 \mu \mathrm{n}$ and $12 \mu \mathrm{n}$ bands on geostationary and polar orbiting infrared radiometers and imagers. To improve detection purposes, imager applications for the MODerate Resolution Imaging Spectro-radiometer (MODIS) instrument onboard NASA Terra and Aqua spacecraft and the Visible Infrared Imager Radiometer Suite (VIIRS) instrument onboard Suomi NPP were subsequently developed to provide better discrimination of ash from water vapor and ice clouds than the traditional split-window imager techniques, as well as to improve height assignment for the ash cloud. These observations and techniques still provide the backbone and the lion's 
share of most of the operational satellite data and imagery used by the international Volcanic Ash Advisory Centers (VAAC).

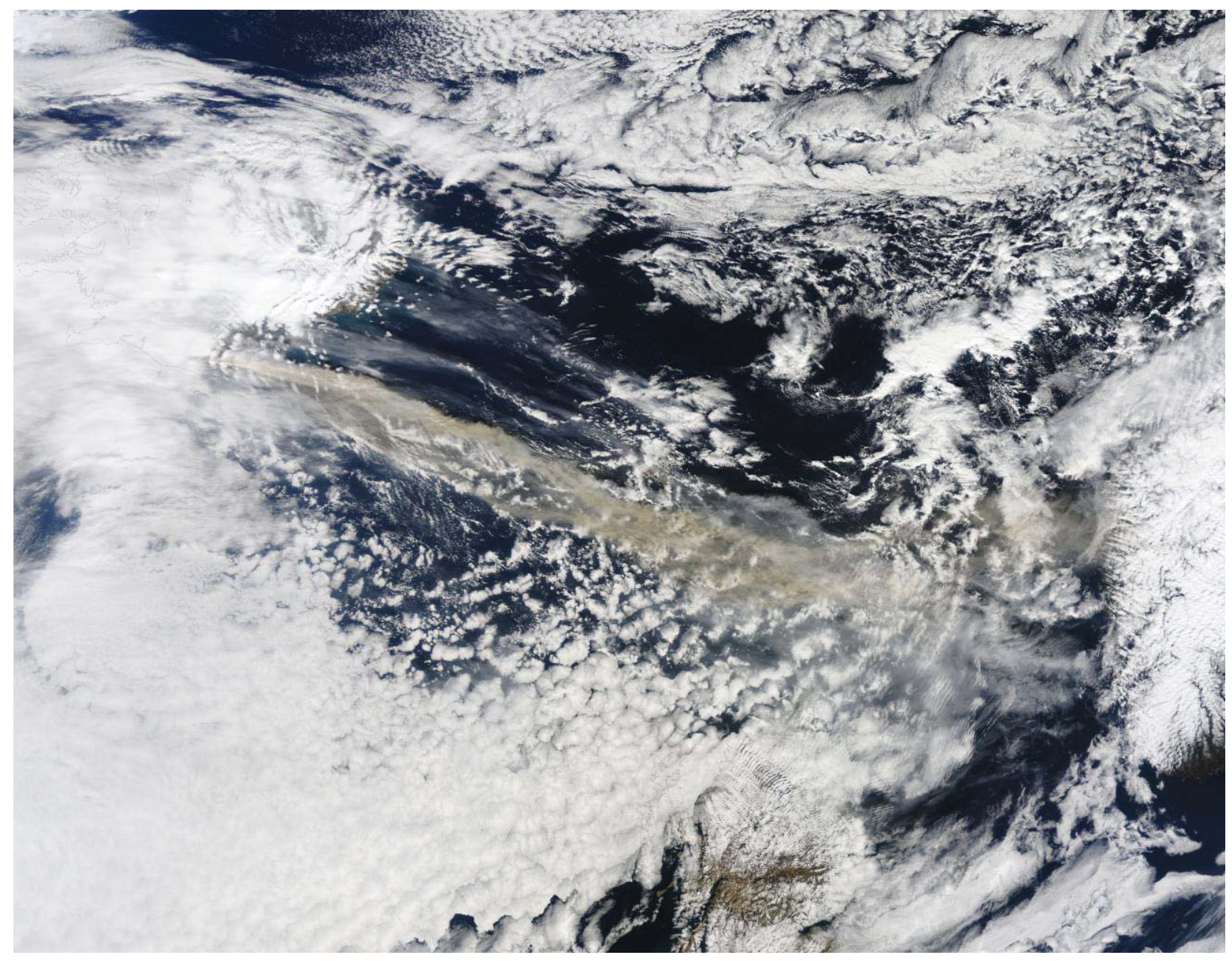

Figure 2. Moderate Resolution Imaging Spectroradiometer (MODIS) ash flow image from 15 May 2010 depicting onflow of dispersive cloud over Great Britain.

Since the launch of the Aura satellite mission as part of NASA's Aqua Train (A-Train) of Earth observing satellites in the last decade, Chemistry and aerosol applications for the Ozone Monitoring Instrument (OMI) onboard the Aura spacecraft have added additional information on the location of volcanic ash clouds, especially their horizontal, areal extent. Using sulfate aerosol as a proxy for ash, these observations (Dobson units) are processed in near-real time to produce improved horizontal dispersion maps, and indices for volcanic ash and sulfate aerosols. The Ozone Mapper and Profiler Suite (OMPS) onboard Suomi NPP launched in November of 2011 is the first operational implementation of this capability by NASA and NOAA. This capability will continue to be available on future, planned NOAA Joint Polar Satellite System (JPSS) satellites. Since these observations are from polar orbiting satellites, they are especially important at higher latitudes where geostationary imagery is not generally available such as in the Alaska VAAC's area of responsibility (AOR) and in the arctic regions of the London 
VAAC AOR. As figure 3 shows, the particular strength of these observations is the horizontal mapping of the ash plume.
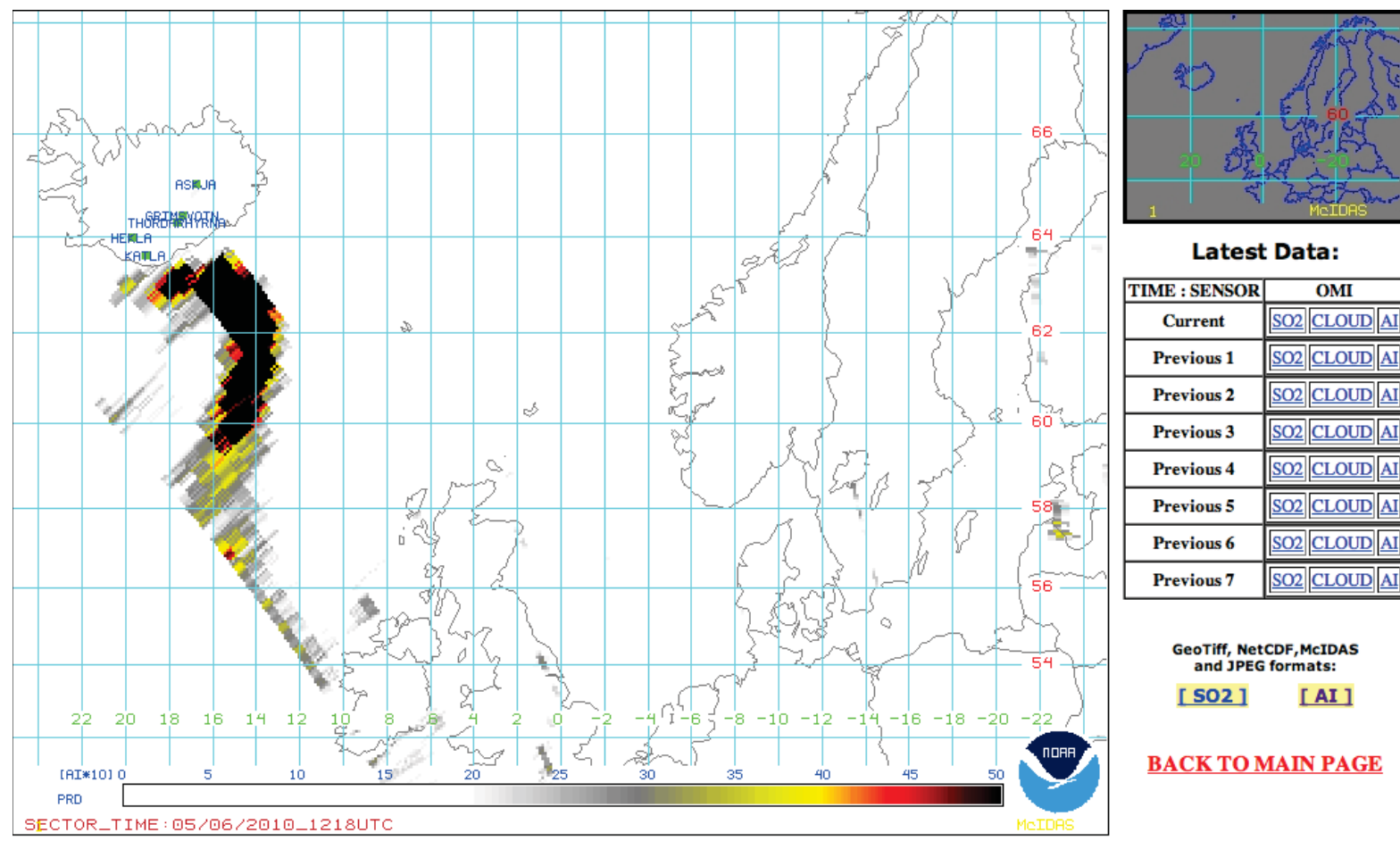

Latest Data:

\begin{tabular}{|c|c|}
\hline TIME : SENSOR & OMI \\
\hline Current & \begin{tabular}{|l|l|l|}
$\mathrm{SO} 2$ & CLOUD \\
\end{tabular} \\
\hline Previous 1 & \begin{tabular}{|l|l|l|}
$\mathrm{SO} 2$ & CLOUD \\
\end{tabular} \\
\hline Previous 2 & 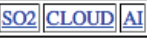 \\
\hline Previous 3 & \begin{tabular}{|l|l|l|l|}
$\mathrm{SO} 2$ & $\mathrm{CLOUO}$ \\
\end{tabular} \\
\hline Previous 4 & \begin{tabular}{|l|l|l|l|}
$\mathrm{SO} 2$ & $\mathrm{CLOUD}$ \\
\end{tabular} \\
\hline Previous 5 & \begin{tabular}{|l|l|l|l|}
$\mathrm{SO} 2$ & CLOUD \\
\end{tabular} \\
\hline Previous 6 & $\begin{array}{lll}\underline{\mathrm{SO} 2} & \mathrm{CLOUD} & \mathrm{AI} \\
\end{array}$ \\
\hline Previous 7 & \begin{tabular}{|l|l|l|l|}
$\mathrm{SO} 2$ & CLLOUD \\
\end{tabular} \\
\hline
\end{tabular}

GeoTiff, NetCDF,McIDAS

[SO2 ] I AI

BACK TO MAIN PAGE

Figure 3. OMI retrieval of volcanic ash index during the Eyjafjallajökull eruption on May 6, 2010 .

The Multi-angle Imaging SpectroRadiometer (MISR) instrument onboard Terra provides unique stereoscopic data for volcanic ash that can be useful for resolving the altitude and extent of volcanic ash layers and for calibration and validation of the other volcanic ash applications. The value is primarily qualitative, however, since the vertical resolution of the sensor is on the order of a kilometer. For highly accurate measurements of the vertical extent of an ash plume, a satellite based lidar would be preferred.

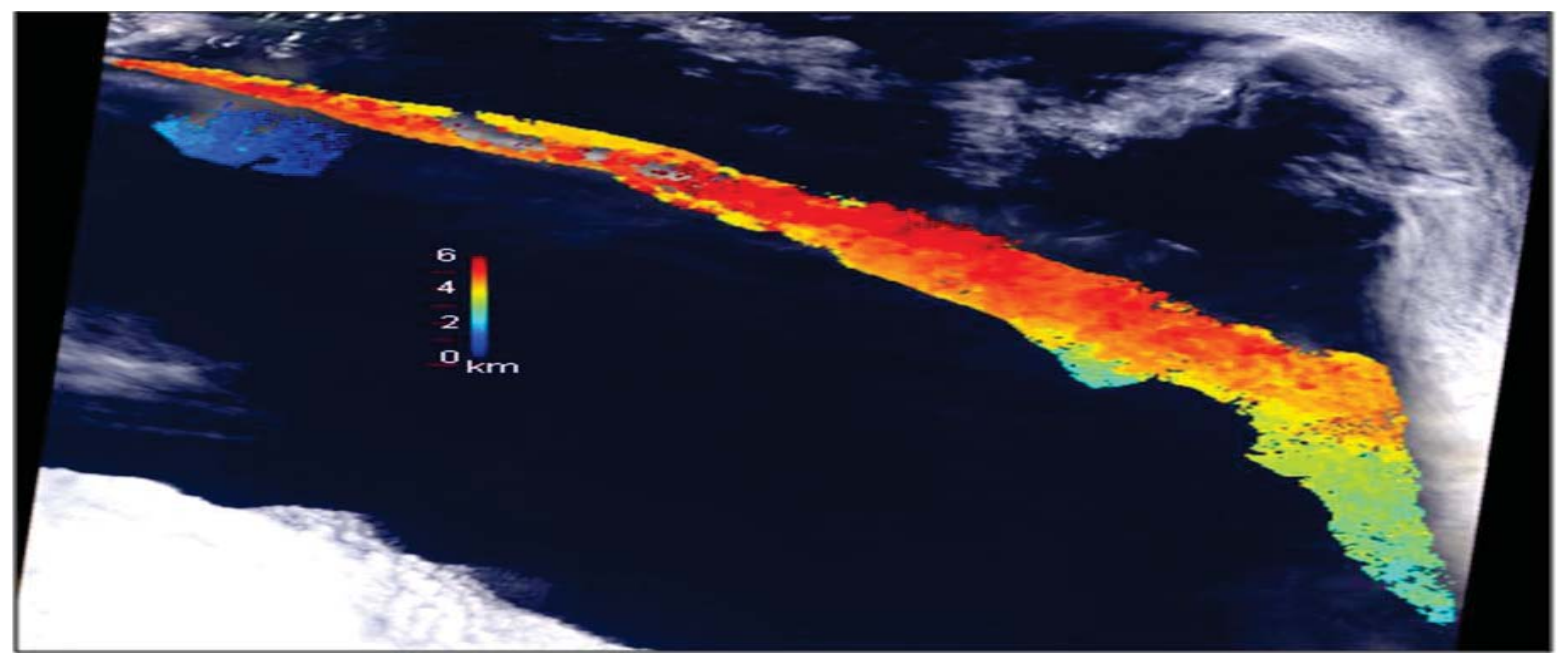

Figure 4. Multi-angle Imaging SpectroRadiometer (MISR) Stereo-Derived plume heights on May 7, 2010. 
Applications for the Caliop lidar onboard the NASA Cloud-Aerosol Lidar and Infrared Pathfinder Satellite Observations (CALIPSO) satellite provide very accurate estimates of volcanic ash altitude, concentration and various aerosol properties. Retrievals of lidar backscatter can also provide very accurate estimates of volcanic ash layering. Lidar color ratio and depolarization data clearly distinguish volcanic ash from ice. Together, these data can very accurately initialize dispersion models and improve forecasts. Constrained with measurements of microphysical properties of the ash from other satellites or extinction to mass ratios from in situ instruments, these data can provide very accurate estimates of volcanic ash concentration.

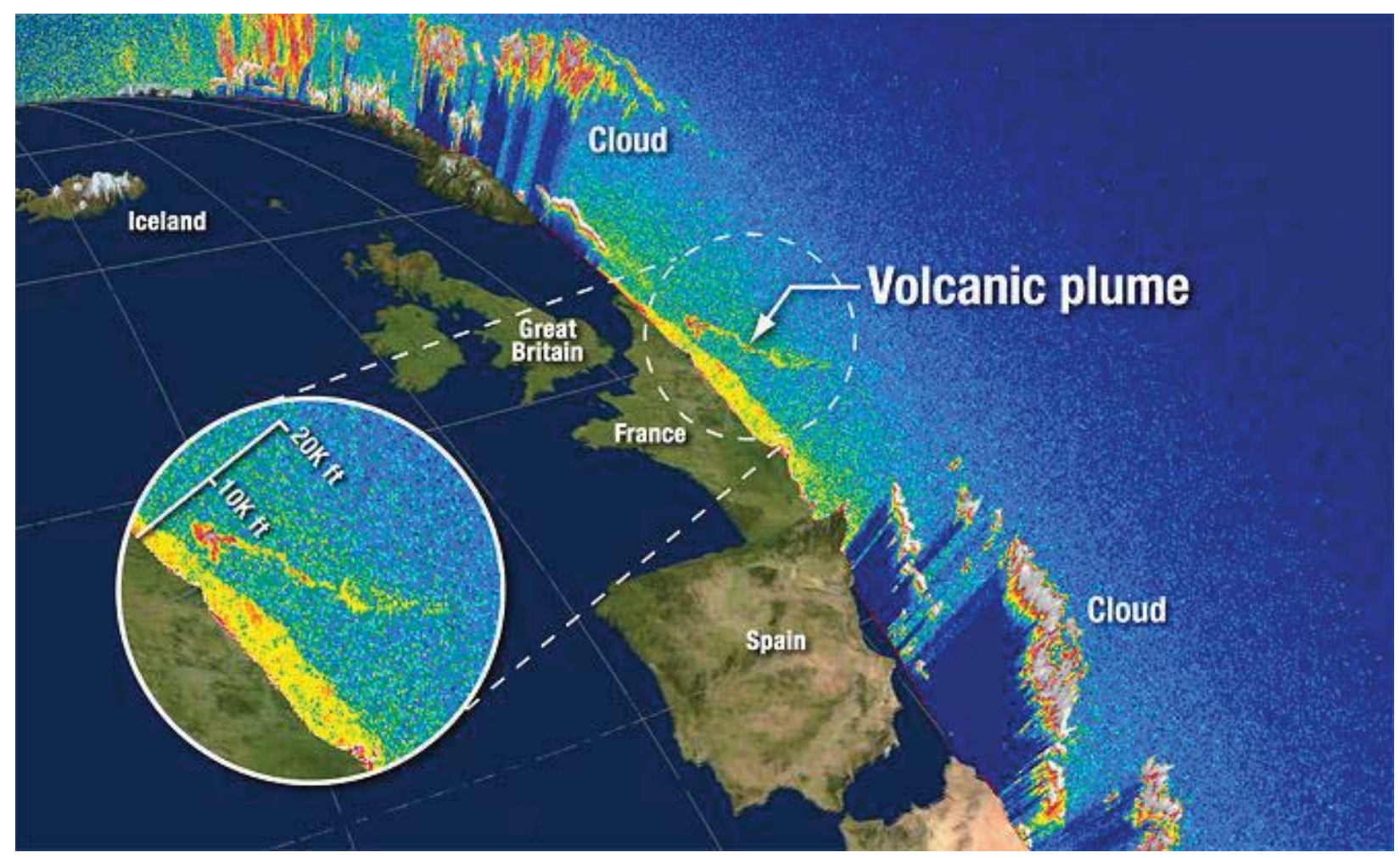

Figure 5. April 17, 2010 Caliop $532 \mathrm{~nm}$ total attenuated backscatter identifying volcanic ash plume from the eruption of the Eyjafjallajökull volcano in Iceland

\section{Conclusion}

The satellite based sensors which are currently deployed each have unique contributions to make toward providing a more complete understanding of the 3-dimensional distribution of a volcanic ash plume. Traditional visual and infrared imagers can identify the horizontal extent of ash clouds if they are not obscured by clouds. Ozone mapping instruments can do this too and they are not generally constrained by clouds. Since they employ ultra-violet backscatter to detect sulfate aerosols, however, they are limited to daytime applications. Although space-borne lidar are not ideal instruments for the initial detection of ash (since they tend to have very narrow beam-widths, $100 \mathrm{~m}$ in the troposphere), Vernier et al (2013) have most recently demonstrated that they hold the key to accurately depicting the 3-dimensional structure of 
ash plumes after lidar observations (ash curtains) are assimilated over several days by high order dispersion models such as those used by the VAACs. This is because of their very high vertical resolution, particle distribution properties, and their ability to easily differentiate between clouds, ice, ash and sulfate aerosols.

Ideally, operational models for forecasting volcanic ash concentration and dispersion patterns would be adapted to assimilate individual data and hybrid retrievals based on a combination of these satellites. This includes imager data from MODIS and VIIRS, chemistry and aerosol data from OMI an OMPS on Aura and Suomi NPP/JPSS and lidar aerosol data form Caliop or future space-borne lidar. This approach would allow their combined, unique strengths to provide a more accurate initial state of the source variables of a volcanic ash cloud. Individually, their strengths are significant. Together, however, they can be used to better estimate critical quantities that are extremely difficult to measure. Mass loading and aerosol concentration come immediately to mind as they remain a source of continuing challenge and contention. The purpose of this paper, then, is to inspire the science community to take this synergistic approach to model assimilation. This is needed to improve dispersion model forecasts well enough to be used more reliably by the Volcanic Ash Advisory Centers than the recent state of the art has yet allowed.

\section{References}

Buis, A. (2010). NASA Satellite Helps Measure Iceland Volcanic Plume. http://www.jpl.nasa.gov/news/news.cfm?release=2010-136

Carn, S.A., Krueger, A.J., Krotkov, N.A., Yang, K., \& Evans, K. (2008). Tracking volcanic sulfur dioxide clouds for aviation hazard mitigation. Natural Hazards.

Carn, S.A., A.J. Krueger, N.A. Krotkov, K. Yang, and K. Evans (2008). Tracking volcanic sulfur dioxide clouds for aviation hazard mitigation. Natural Hazards, doi:10.1007/s11069-008-9228-4

Fairlie, T. D., J. Szykman, A. Gilliland, R. B. Pierce, C. Kittaka, S. Weber, J. Engel-Cox, R. R. Rogers, J. Tikvart, R. Scheffe, F. Dimmick (2009), Lagrangian sampling of 3-D air quality model results for regional transport contributions to sulfate aerosol concentrations at Baltimore, MD, in summer 2004, Atmospheric Environment, Vol. 43, No. 20, 3275-3288.

Pavolonis, M. J., 2010: Advances in extracting cloud composition information from space borne infrared radiances: A robust alternative to brightness temperatures. Part I: Theory. J. Applied Meteorology and Climatology, 49, 19922012.

Sanderson K., Questions fly over ash-cloud models. Published online 27 April 2010 | Nature 464, 1253 (2010) | doi:10.1038/4641253a.

Vernier, J-P, T.D. Fairlie, J.J. Murray, C. Trepte, A. Tupper, D. Winker, J. Pelon, A. Garnier, J. Jumelet, M. Pavolonis (2013). An advanced system to monitor the 3-D structure of diffuse volcanic ash clouds. J. Applied Meteorology and Climatology. Accepted and in press.

Vernier, J.-P., J. P. Pommereau, A. Garnier, J. Pelon, N. Larsen, J. Nielsen, T. Christensen, F. Cairo, L. W. Thomason, T. Leblanc, and I. S. McDermid (2009), Tropical stratospheric aerosol layer from CALIPSO lidar observations, J. Geophys. Res., 114, D00H10, doi:10.1029/2009JD011946. 
Vernier, J.-P., J. Jumelet, Advances in forecasting volcanic plume evolution, 6 May 2011, SPIE Newsroom. DOI: 10.1117/2.1201103.003530.

Winker, D. M., et al. (2010), The CALIPSO mission: A global 3D view of aerosols and clouds, Bull. Am. Meteorol. Soc., 91, 1211-1229, doi:10.1175/2010BAMS3009.1.

Winker, D. M., Z. Liu, A. Omar, J. Tackett, and D. Fairlie (2012), CALIOP observations of the transport of ash from the Eyjafjallajökull volcano in April 2010, J. Geophys. Res., 117, D00U15, doi:10.1029/2011JD016499.

Yang, K., X. Liu, N. A. Krotkov, A. J. Krueger, and S. A. Carn

Estimating the Altitude of Volcanic Sulfur Dioxide Plumes from Space Borne Hyper-spectral UV Measurements, Geophys. Res. Lett., (2009). 